\title{
EDITORIAL
}

\section{Respuesta en México al actual brote de influenza AHINl}

A nualmente en México las neumonías representan una de las principales causas de morbilidad y mortalidad. Contrario a lo que se piensa comúnmente, los virus de influenza circulan en México de igual forma que como lo hacen en otros países del hemisferio norte, y contribuyen de manera importante a la carga de la enfermedad causada por neumonías. De hecho, durante los últimos años el InDRE (Instituto de Diagnóstico y Referencia Epidemiológicos de la Secretaría de Salud) ha identificado múltiples casos de influenza estacional, generalmente causados por virus de influenza AH3N2 y algunos casos por influenza B. Por ejemplo, en un estudio realizado en México en 1998, el InDRE reportó más de 100 muestras positivas para influenza de un total de 1017 muestras clínicas, en las que se identificaron los virus A/Sydney/05/97-like y B/Beijing/184/93-like, los cuales estuvieron incluidos en la recomendación de la OMS para la elaboración de la vacuna en el hemisferio norte durante el año en que se realizó dicho estudio. ${ }^{1}$

Los virus de la influenza A y B son de relevancia médica en México y en el mundo por causar infecciones respiratorias severas que pueden ocurrir en forma epidémica estacional o interpandémica casi todos los inviernos en el hemisferio norte; o que se presentan periódicamente tras la aparición de un nuevo virus de influenza A en forma pandémica, por afectar a todos los continentes, y que con frecuencia están asociadas con un aumento significativo en los índices de hospitalización y mortalidad. Estas variaciones se deben al comportamiento biológico de los virus ARN de influenza, conformados por genomas inestables, los cuales sufren frecuentes variaciones antigénicas y crean una fuente constante de poblaciones susceptibles a estos virus. ${ }^{2}$

La capacidad de los virus de la influenza A y B de sufrir cambios antigénicos graduales en sus dos antígenos de superficie, la hemaglutinina y la neuraminidasa, complica la vacunación contra esta enfermedad. El tipo de cambios antigénicos menores o deslizamientos antigénicos resulta de la acumulación de mutaciones puntuales de los genes que transcriben para estas proteínas. La presencia de inmunidad en las poblaciones a los antígenos de superficie reduce el riesgo de infección y en el caso de que se establezca la infección, disminuye la severidad de la enfermedad. Los anticuerpos dirigidos contra un determinado tipo o subtipo del virus de la influenza ofrecen protección limitada o ninguna contra otro tipo o subtipo. Los subtipos H1N1, H1N2, y H3N2 de la influenza A son los que han circulado en los últimos años, mientras que el subtipo H2N2 circuló en humanos en la década de los noventa. Sin embargo, cepas de influenza $A$ en aves pueden contener combinaciones de alguno de los 15 posibles subtipos de hemaglutininas y de los 9 subtipos de neuraminidasas. Esta es la razón para la incorporación de tres cepas diferentes en la vacuna correspondiente a cada periodo de actividad de influenza. Y es por ello que el dinámico proceso de variaciones antigénicas asegura la renovación constante de huéspedes susceptibles en las poblaciones y constituye también la base virológica para las epidemias. ${ }^{2-4}$

En ocasiones pueden ocurrir cambios antigénicos mayores en el caso de la influenza A con la aparición de combinaciones de hemaglutinina y neuraminidasa que no han afectado previamente a las poblaciones, lo cual se ha asociado a pandemias, como fue el caso durante la pandemia de la "influenza española" en 1918-1919, o las de 1957 y 1968, con resultados catastróficos. Los virus de la influenza pueden causar pandemias durante las cuales las tasas de infección y muerte por complicaciones relacionadas con la enfermedad se incrementan considerablemente a nivel mundial (cuadro I). La influenza tiende a afectar gravemente a todos los grupos etarios durante estos episodios. ${ }^{3}$ Es por ello que en anticipación a la aparición de una pandemia de influenza y su potencial para desencadenar graves consecuencias de 


\section{Cuadro I}

\section{Complicaciones asociadas} A LA INFLUENZA ESTACIONAL O PANDÉMICA

- Neumonía secundaria bacteriana (Streptococcus pneumoniae, Staphylococcus aureus, Hemophilus influenzae)

- Neumonía viral primaria

- Exacerbaciones de bronquitis crónica, asma y otras enfermedades pulmonares

- Exacerbaciones de enfermedades cardiovasculares (insuficiencia cardiaca congestiva)

- Síndrome de choque tóxico

- Encefalopatía / Encefalitis

salud, sociales y económicas, es imprescindible el establecimiento de planes de preparación y respuesta. ${ }^{1,3} \mathrm{La}$ prensa nos inunda cotidianamente con noticias sobre los riesgos de una pandemia de influenza, y las organizaciones internacionales de salud pública prestan la debida atención a los brotes de influenza aviar con gran detalle por medio de programas de vigilancia epidemiológica en diferentes sitios a nivel mundial. ${ }^{3}$ Sin embargo, resulta claro que existe una tendencia a separar el riesgo de una pandemia de influenza, particularmente el riesgo de que la influenza aviar o porcina pueda adaptarse (por medio de rearreglos genéticos o mutaciones) al epitelio respiratorio humano y subsecuentemente transmitirse de persona a persona, del impacto de salud poblacional ocasionado anualmente por la influenza estacional. También es ilustrativo el riesgo latente de algunas cepas virales circulantes -como la cepa de influenza AH1N1 descrita actualmente en México y en otros países- de diseminarse por medio de la transmisión respiratoria de persona a persona, sobre todo cuando hay sustituciones antigénicas mayores. ${ }^{2,4}$ Hasta el 7 de mayo del 2009, la Organización Mundial de la Salud reportaba más de 1 800 casos confirmados de influenza AH1N1 en 23 países. Aunque el análisis filogenético de la cepa demuestra que es de origen euroasiático, hasta el momento se desconoce el origen específico del brote actual de influenza AH1N1. ${ }^{5}$

En general, la mayoría de las infecciones sintomáticas por influenza son clínicamente autolimitadas, la enfermedad aguda puede variar de un cuadro febril agudo leve a cuadros debilitantes graves y en ocasiones asociarse a complicaciones secundarias. Dentro de éstas, la neumonía viral primaria por el virus de influenza y la neumonía bacteriana secundaria son las más relevantes. Otras complicaciones clínicamente importantes son las exacerbaciones de procesos pulmonares crónicos como el asma o la bronquitis crónica y las exacerbaciones de enfermedades cardiovasculares como la insuficiencia cardiaca congestiva (cuadro I). ${ }^{4}$ El riesgo de desarrollar complicaciones graves de la influenza es más elevado en personas en los extremos de la vida, así como en aquellos con condiciones médicas de base. En ciertas personas, la influenza puede exacerbar estas condiciones médicas. Es el caso de algunas personas con neumopatías crónicas o enfermedad cardiaca, en quienes puede producir neumonías bacterianas secundarias o neumonía primaria por influenza. La etiología de las neumonías secundarias es la siguiente: Streptococcus pneumoniae, Staphylococcus aureus, seguida de Haemophilus influenza no tipificable. ${ }^{6-7}$ Las epidemias de influenza han sido responsables de un promedio de 36000 muertes y más de doscientos mil hospitalizaciones por año en países como Estados Unidos, afectando a todos los grupos etarios, pero principalmente a niños menores de 2 años y adultos mayores de 65 años. En México, estimaciones recientes demuestran que hasta 10000 personas mueren cada año por complicaciones asociadas a la influenza estacional. ${ }^{8}$ La influenza estacional o interpandémica es en realidad indivisible de la influenza pandémica y puede asociarse a las mismas complicaciones médicas, pero con una dispersión rápida y produciendo cuadros de insuficiencia respiratoria aguda en diferentes grupos de edad.

Es por lo anterior que la preparación para una pandemia de influenza debe desarrollarse conjuntamente con el establecimiento de programas de prevención y control de influenza estacional, tales como el establecimiento de políticas de vacunación anual contra influenza estacional que se traduzcan en el el fortalecimiento de programas de vacunación contra influenza como uno de los pilares fundamentales de los planes de preparación para una pandemia de influenza. De esta forma, tener un programa bien establecido de vacunación que incluya aspectos programáticos como la distribución, el personal requerido y los insumos para la administracion de la vacuna, permitirá el uso de este programa para distribuir y administrar (cuando esté disponible) la vacuna contra la influenza pandémica; o de antivirales, antipiréticos, o antibióticos. Por otro lado, las empresas farmaceúticas, al tener un mercado existente con un incremento justificado en la demanda de vacuna de influenza estacional, podrán justificar la producción de vacuna contra la cepa pandémica cuando esté disponible. ${ }^{2-3}$

\section{Influenza aviar, influenza porcina y pandemias}

La influenza aviar es provocada por un grupo de virus de influenza A que normalmente sólo infectan a las aves $\mathrm{y}$, con menor frecuencia, a los cerdos. En las aves, el virus de la influenza es capaz de multiplicarse tanto en el siste- 
ma respiratorio como en el intestino y, una vez eliminado por las heces, contamina el medio ambiente. El virus se puede aislar de la cloaca de aves acuáticas como los patos y de las lagunas donde nadan. Aunque los virus de la influenza aviar son muy específicos en cuanto a la especie que infectan, en ocasiones han atravesado la barrera entre especies para infectar al ser humano. Uno de los factores que se han considerado relevantes en la generación de estos brotes ha sido el incremento poblacional en zonas urbanas y la expansión en la industria productora de pollos y sus derivados a escala mundial, principalmente en el sureste asiático, lo que condiciona un contacto cercano entre humanos y aves de corral. Las aves de corral a su vez han sido contagiadas por aves migratorias acuáticas infectadas por estos virus. En este intercambio ecológico entre aves y humanos, el cerdo se considera también como un reservorio estratégico para la recombinación viral.

El riesgo de la influenza aviar de transformarse en una pandemia radica en la habilidad de algunas de estas cepas virales, particularmente aquellas consideradas como de alta patogenicidad en aves, para cruzar la barrera de especies animales y ocasionar casos en humanos, como ya ha ocurrido en los múltiples brotes descritos en la última decada. ${ }^{3-4}$ No obstante, el mayor riesgo reside en que estos virus se recombinen con cepas humanas (H3N2), ya sea en el humano o en un huésped intermedio, como los cerdos, y generen híbridos virales con potencial de diseminación global por su transmisibilidad de persona a persona, y probablemente con elevada patogenicidad por la ausencia de inmunidad previa en las poblaciones, como lo demuestra el brote actual de influenza AH1N1 (antes porcina) en México. Es posible especular en estos momentos que el origen de la actual cepa circulante proviene de la combinación de cepas humanas con cepas de influenza aviar, teniendo como reservorio del evento de recombinación al cerdo. Después de la generación de una cepa recombinante, en este caso una cepa H1N1 porcina, un número elevado de individuos resulta susceptible inmunológicamente a esta nueva cepa.

\section{Retos inmediatos para mitigar el impacto de una potencial pandemia}

La influenza epidémica o pandémica puede afectar a un importante número de personas de todos los grupos etarios. ${ }^{7}$ Sin embargo, de manera similar a la pandemia de influenza de 1918-1919, el mayor impacto en términos de mortalidad ha ocurrido en el grupo de adultos jóvenes, lo que indica quizá una respuesta inmune exhuberante en ausencia de inmunidad previa. ${ }^{9}$ La enfermedad por influenza en los casos recientes ha requerido frecuentemente de atención médica y hospitalización, y contribuido sustancialmente al exceso en el número de hospitalizaciones y muertes, en un comportamiento epidemiólogico similar al de la pandemia de 1918-1919. Desde un punto de vista epidemiológico, la cepa de influenza AH1N1 parece haberse generado por una sustitución antigénica mayor que hasta el momento ha producido algunos casos de neumonía severa (no es claro si primaria viral o secundaria bacteriana) en población joven con una tasa

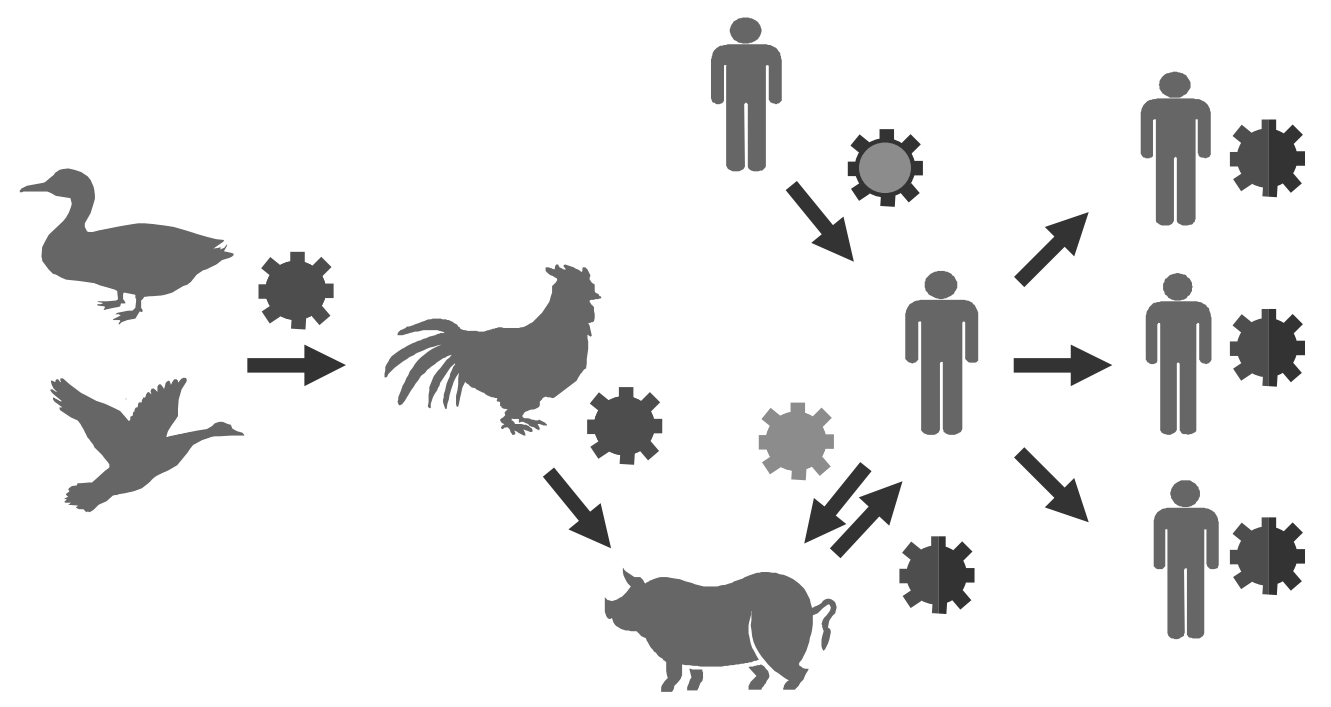

Figura I. Eventos de recombinación genética entre aVes, Cerdos y humanos (probable mecanismo de génesis del ACTUAL VIRUS AH1N1 DE LA INFLUENZA 
de ataque de 1.3 (Stefano Bertozzi, comunicación personal) y con una baja tasa de letalidad para un país como México, que cuenta con aproximadamente 110 millones de habitantes.

La diferencia en este momento con otros puntos en la historia de la respuesta ante estas epidemias es la actual disponibilidad de mejores sistemas de vigilancia epidemiológica y de difusión de la información; la institución temprana de medidas de distanciamiento social; mejores protocolos de control de infecciones hospitalarias; la disponibilidad de antivirales efectivos para disminuir la transmisión, los síntomas y potenciales complicaciones asociadas, y un mejor manejo médico en terapias intensivas en pacientes con insuficiencia respiratoria severa.

El impacto de la actual epidemia de influenza en México ha sido significativamente controlado por las medidas impuestas por las autoridades de salud pública en México. La Subsecretaría de Prevención y Promoción de la Salud de la Secretaría de Salud, en coordinación con el InDRE y la Dirección General de Epidemiología han actuado en forma temprana, efectiva y transparente. Las medidas utilizadas para controlar el actual brote de influenza en México han incluido la vigilancia epidemiológica de casos de neumonías bacterianas en general y confirmados de influenza en salas de emergencia, hospitales y terapias intensivas, así como de contactos, para prevenir la transmisión; el uso de oseltamivir y zanamivir para disminuir síntomas y potenciales complicaciones; la aplicación estricta de medidas de control de infecciones hospitalarias; el aislamiento de casos, y la posible cuarentena de contactos. México ha mostrado al mundo la aplicación moderna y acertada de las medidas de distanciamiento social en forma temprana para el control de los brotes de influenza (cierre de escuelas, iglesias, eventos deportivos, etc...). Estas medidas se han aunado a una comunicación efectiva y veraz con la sociedad civil y la educación de la población respecto de la epidemia. La colaboración internacional en el control de pandemias de influenza es crítica. En este sentido, México ha actuado estrechamente con organizaciones internacionales en la confirmación laboratorial y los análisis epidemiológicos concernientes al brote.

Finalmente, es importante recalcar que, históricamente, la pandemia de influenza de 1918-1919 se inició con un brote inicial durante la primavera de 1918, el cual se controló, pero el contagio reemergió en forma explosiva durante el invierno de 1918. Es crítico considerar estos antecedentes históricos en la epidemiología de las pandemias en anticipación a laépoca invernal de 2009, pues la posible inclusión de esta cepa de influenza AH1N1 en la mezcla antigénica vacunal será una decisión que requerirá del liderazgo de expertos y organizaciones de salud pública internacional en colaboración con la industria farmaceútica. Es prematuro especular acerca de la progresión histórica de la actual epidemia de influenza. Sin embargo, queda el registro de que México identificó y notificó en forma temprana a las autoridades sanitarias mundiales de la actual epidemia de influenza porcina, así como dela efectiva respuesta nacional para controlar su impacto en la población con medidas de distanciamiento social.

\section{Referencias}

Santos-Preciado Jl, Franco-Paredes C. Influenza vaccine in childhood: a preventive strategy of national priority. Salud Publica Mex 2004;46:498-500. Santos-Preciado Jl, Franco-Paredes C. Influenza y la pandemia que viene. En: Diagnóstico y tratamiento en la práctica médica. Ed. Narro Robles E. 2007, segunda edición.

Franco-Paredes C, Tellez I, Del Rio C, Santos-Preciado Jl. Pandemic influenza: impact of avian influenza. Salud Publica Mex 2005;2: 47(2): 107-109.

Kieny MP, Costa A, Carrasco P, Perichov Y, Franco-Paredes C, SantosPreciado Jl, et al.A global pandemic influenza vaccine action plan.Vaccine 2006;24:6367-6370.

World Health Organization. Epidemic and pandemic alert response. Disponible en: http://www.who.int/csr/don/2009_05_07/en/index.html. Con acceso: mayo 7,2009.

Morens DM, Taubenberger JK, Fauci AS. Predominant role of bacterial pneumonia as a cause of death in pandemic influenza: implications for pandemic influenza preparedness.J Infect Dis 2008; 198:962-970. Kilbourne ED. Studies on influenza in the pandemic of 1957-1958. III. Isolation of influenza A (Asian strain) viruses from influenza patients with pulmonary complications; details of virus isolation and characterization of isolates, with quantitative comparison of isolation methods.J Clin Invest 1959; 38(I Part 2):266-274.

Frenk J. Mexico's fast diagnosis. Op-ed contribution. The New York Times. Abril 30, 2009. Disponible en: http://www.nytimes.com/2009/05/0I/ opinion/0 Ifrenk.html!scp=|\&sq=julio\%20frenk\&st=cse. Con acceso: mayo $7,2008$.

Seo SH, Hoffmann E, Webster RG. Lethal H5NI influenza viruses escape host anti-viral cytokine responses. Nat Med 2002 Sep;8(9):950-954.

\footnotetext{
${ }^{1}$ Asesor en vacunas de influenza, Organización Mundial de la Salud, Ginebra, Suiza

2 Departamento de Salud Global, Rollins School of Public Health, Universidad de Emory, Atlanta GA, EU

${ }^{3}$ Unidad de Medicina Experimental, Facultad de Medicina, Universidad Nacional Autónoma de México, México, DF.
} 